\title{
Factors Influencing Moscow University Students' Level of Trust in the Russian State Mainstream Media News
}

\author{
Phillip Y. Freiberg \\ Graduate School of Public Administration \\ National Institute of Development Administration \\ 148 Serithai Road, Klong-Chan, Bangkapi, Bangkok 10240 \\ Thailand \\ Kasemsarn Chotchakornpant, Ph.D \\ Graduate School of Public Administration \\ National Institute of Development Administration \\ 148 Serithai Road, Klong-Chan, Bangkapi, Bangkok 10240
}

Received: Mar. 10, 2021 Accepted: Mar. 31, 2021 Online published: Apr. 8, 2021

doi:10.5296/jpag.v11i2.18516 URL: https://doi.org/10.5296/jpag.v11i2.18516

\begin{abstract}
In the modern social sciences, the concept of confidence or trust is considered an essential element of the socio-cultural potential of each given society. Trust in the institutions of the socio-political system is the basis and condition for its effectiveness and is the central element of its [the system] legitimation. Many researchers view trust in the media from the point of view of public confidence in the authorities, which is formed by providing the media with this or that information.

Trust is based on a cognitive process that discriminates among persons and institutions that are trustworthy, distrusted, and unknown. Therefore, the concept of trustworthiness is central to understanding and predicting trust levels.

In this work, we viewed trust as a manifestation of social capital. At the same time, trust antecedents are trustworthiness and propensity to trust.

Proceeding from the resource approach, the credibility (trustworthiness) of the media is a set of ideas and attitudes of the audience: reflecting the public's expectations that the media will
\end{abstract}


implement some of the practices that allow the audience to increase or maintain their social resources.

The goal of this work was to establish a causational relationship between the level of trustworthiness (social capital) of the political power (via its administration and mass media) and the level of trust in its messages by youth as they are transmitted via MSM; while the rise of information through the Internet is rising in Russia and the overall propensity to trust is falling.

Keywords: Social Capital, trust, propensity of trust, mainstream media, alternative internet media, Russia, runet

\section{Introduction}

Trust is an important factor for a well-functioning public administration apparatus since trust acts as a guarantor of social justice and an indicator of social qualities.

The term 'trust' is often used to refer to trustworthiness - a characteristic of the one who is trusted by others (Kiyonari, 2006). Trust gives us confidence that others will act as we might expect; and while trust may be based on first-hand experience, it is often a phenomenon of subjective perception. Public and government institutions, just like businesses need a reputation for reliability to bring tangible benefits, such as easier acceptance of new policies, and more ambitious reform agendas. In essence, governments cannot function effectively without the trust of citizens. The Organization for Economic Co-operation and Development, 2017 report titled, Trust and Public Policy: How Better Governance Can Help Rebuild Public Trust, reads "trust influences the relationship between citizens and government, and in turn has an impact on the outcomes of public policy" (OECDPublic Governance Reviews, 2017).

In 2019 Edelman Trust Barometer indicated that across the world "Media remain[ed] the least trusted institution" (Edelman, 2019). In Russia over the past twenty years, the level of trust in the media within the system of public trust remains quite low. This is mainly due to the generally low level of trust by the Russians towards social and political institutions associated with the political and economic transformations over the last 30 years.

Social imperatives and the tasks of preserving the real sovereignty of the nation-states in the field of information security and counteraction to the information intervention by the foreign global elites lay before sovereign states the task of more fully incorporating mass media and especially the Internet and social networks in the subject field of modern politics and public administration. Presently with the spread of the new technologies that enable alternative ways to send and receive information bypassing official communication channels, the government has lost the prerogative of informing the public about its policies, and it has certainly lost unquestionable public trust in the usefulness of these policies because the public now has other sources of news and platforms where they can get alternative views on the government activities.

Support or opposition towards the government actions is based on the public's trust either in the State Mainstream Media (owned or controlled by the Russian state) or the independently 
owned Alternative News (present almost exclusively online and social networks dominated by the virtual opinion leaders). And public trust in its turn is the manifestation of these media's trustworthiness or their social capital i.e., capital or resources to influence public opinion. If the trustworthiness and social capital of the official narrative are low, the public will not support the government projects.

Therefore, the manifestation of mistrust (or distrust) towards government messages transmitted via MSM creates a threat of violation of the communication link between society and the government (political and administrative systems), as well as a lack of trust in the latter. Such a development in the future may contribute to the growth of protest sentiments or civil absenteeism and even lead to destabilization of the socio-political situation in the country.

The logic underlying our conceptualization is that trust in media messages describing the reality (i.e. news) stems from the confidence in past actions (i.e. trustworthiness or social capital) of the institute that transmits these messages, and additionally influenced by the messages about the reality stemming from the alternative sources, as well as the individual tendency to believe messages from the groups outside immediate family realm (i.e. Propensity to Trust).

We argued that if the Mainstream Media (i.e., government mouthpiece) exhibit the social capital, it is trustworthy in the eyes of the public, in other words, the public trusts it (has confidence in it), and henceforth trusts (beliefs) its messages (news), in the absence of other external influences.

Consequently, if the Alternative Internet Media, being in opposition to the MSM and its owner/controlled the government- exhibits the social capital, it is trustworthy in the eyes of the public, in other words, the public trusts it (has confidence in it), and henceforth trusts (believes) its messages (news), it (the public) will trust MSM media less, in the absence of other external influences. Therefore the statement " I Trust in MSM news' was interpreted by us as the audience's trust in the fairness of executing media functions of unbiased and accurate informing, presenting all possible points of view on debatable issues, performing the watchdog function in relation to power and refusing to manipulate the audience.

In this research equated Social Capital with Trustworthiness and Trustworthiness with Confidence, thus it is safe to assume that Social Capital equals confidence.

Thus, if the Government- media owner/controller, exhibits the social capital, it is trustworthy in the eyes of the public, in other words, the public trusts it (has confidence in it), and henceforth trusts (believes) its messages (news), in the absence of other external influences.

In summary, we hypothesized that if an organization or institution exhibits Social Capital, it has the capital to influence public minds i.e., it is trustworthy since one of the measurements of Social Capital is trust). Henceforth a trustworthy organization will be trusted (i.e., audience will have confidence in its message), in the absence of other influences.

The primary objectives of this work were: 
To examine the level of trust in the government-controlled/owned Mainstream Media (MSM) i.e. Television, radio, and the Internet among Moscow undergraduate students.

and

To discover the factors affecting the level of trust among Moscow undergraduate students in the information provided by the government-controlled/owned MSM.

The primary questions of this work were:

Do Moscow university students trust the information they get from the government-controlled/owned Russian MSM?

and

What factors weaken the level of students' trust (increase level of distrust) in the information provided by the government-controlled/owned MSM?

The scientific novelty of this work encompassed an analysis of the level of trust of the youth audience in the MSM as an element of the social capital of the Russian government. For that, the author of this work had to analyze the relevance of classical models to the modern socio-political conditions and to espouse new models since the goal and tasks of this dissertation work are largely on the periphery of scientific knowledge. In the theoretical aspect, this thesis is an essential experience in the study of the phenomenon of the modern media and political-administrative communication, its role, and place in the system of modern public management from the standpoint of the implementation of information and communication influence on the public consciousness.

The practical significance of this work is the fact that it proposed an appropriate government policy to regain the trust of the youth to the information stemming from the government-controlled/owned Mainstream Media (MSM).

\section{Literature Review}

In this work, we have undertaken an extensive review of the literature on the topics of media communications, trust, and social capital to determine the extent to which Social Capital Theory and Theory of Trust both help to explain attitudes of the young Muscovites towards the MSM news; i.e., the relationship between the Social Capital of the Russian Government, MSM and Alternative Internet Media (expressed as their trustworthiness i.e., confidence therein) and the level of trust in the State MSM news by the Moscow Youth. Based on literature research we concluded that 'trust' is directly encompassed in the mechanism of legitimization of power and forms the base of maintaining power institutions and the political and economic course chosen by them.

The Bureaucratic Theory of Management, by Max Weber, postulates that social stability is achieved via the many hierarchical positions that redistribute power with the bottom class having less and the top class having the greatest power. The bottom layers of bureaucratic structures are always subject to supervision and control of higher layers. Formal rules and requirements are necessary to ensure uniformity so that all members of the system know exactly what is expected of them (Weber, 2015), (Udy Jr, 1959). 


\section{$\triangle$ Macrothink}

The definitions of trust offered by Mayer et al. (Mayer, 1995) and Rousseau et al. (1998) both include an expectation that another party will perform a particular action. One driver of that expectation is trustworthiness, as Lewis and Weigert (J. David Lewis, 1985) noted that trust is based on a cognitive process that discriminates among persons and institutions that are trustworthy, distrusted, and unknown.

Overall levels of trust are frequently clustered into two broader categories: Systemic or Institutional trust in the realm of public and political institutions; and Interpersonal trust, in the realm of human and social interactions. Trust in the media, being Systemic or Institutional trust, is implemented at various levels of the media system and relies on the internal motivation of the audience to consume the media product, and not based on fear and coercion. Genuine trust, therefore, contributes to the maintenance of effective relationships, the formation of effective feedback between the media and the audience.

In this regard, trustworthiness is the ability to be relied upon; being regarded as honest or truthful. Therefore, we can align trustworthiness with confidence. This ability can be regarded as capital, i.e., intangible assets owned by a person or organization or available or contributed for a particular purpose. According to (Colquitt, Scott, \& LePine, 2007) trust antecedents are Trustworthiness and Propensity to Trust.

Regarding the media, the notions of "media confidence", "media trust" are used simultaneously, but there is no similarity between them. Seligman noted that 'Trust' is different from 'Confidence' in that the confidence rests on knowledge or predictability of the actor's actions, while trust is necessary to maintain interaction in the absence of such knowledge (Seligman, 1998). In our study, therefore, we used the term "trust in media" and equated trustworthiness (social capital) with confidence. For example, Glaeser (1999) discussed whether trust, trustworthiness, and social capital are characteristics of individuals, as well as groups; in their past trusting behavior correlated with trusting behavior and the levels of trust.

\subsection{Trust in the Media}

According to Mayer et al. (Academy of Management Review, July 1995) trust is the willingness of a party to be vulnerable to the actions of another party based on the expectation that the other will perform a particular action important to the trustor, irrespective of the ability to monitor or control that other party (Mayer et al., 1995). Turning to the category of "trust in the media," we defined it as a rationally conditioned (social capital) and emotionally supported (propensity to trust) attitude of the audience to the media, the essence of which is the audience's trust in the fairness of executing media functions of:
i) unbiased informing
ii) accurate informing,
iii) presenting all possible points of view on debatable issues,
iv) performing the watchdog function in relation to power, and
v) refusing to manipulate the audience.

For the purposes of this work, therefore, we proceeded from the resource approach. 
According to (Cunningham, 1978) "Systems theorists maintain that all organizations, to survive, must be able to fulfil certain basic needs.

The credibility (trustworthiness) of the media is a set of ideas and attitudes of the audience, reflecting its expectations that the media will implement some of the practices that allow the audience to increase or maintain their social resources.

At the same time, distrust (untrustworthiness) of the media is the audience's expectation that the media will act in such a way that the social resources of the audience would decrease.

\subsection{Social Capital}

Many studies associate the measurement of Social Capital via such category as trust. For example, our review of the research by the Organization for Economic Co-operation and Development revealed 136 works that measured social capital through measuring trust (OECDPublic Governance Reviews, 2017).

Robert Putnam's five principal components of Social Capital include among others Trust in the community (Putnam, 1995).

Therefore, Social Capital is the intangible asset of any organization. The Social Capital of the political power (and its administrative apparatus) allows it to exert its agenda on the public to gain support for its policies at a minimum and maintain legitimacy at maximum. Since presently governments are quite large and populations are even larger, State Mainstream Media (owned or controlled by the Russian government) is the tool that the political power (and its administrative apparatus) utilize to reach the public and exert influence over it. Henceforth Main Steam Media's success in imposing upon the public a certain agenda is the evidence of its (MSM) social capital.

Grounding our hypothesis on the literature review, in this work we viewed trust or confidence as a manifestation of Social Capital. At the same time according to Colquitt, Scott, \& LePine, (2007) trust antecedents are trustworthiness and propensity to trust. Thus if the institute or organization is trustworthy it means that it possesses social capital to implement its agenda, and visa-versa, if the institute is not trustworthy it is devoid of social capital and therefore doesn't have the resources to implement its agenda, because the public doesn't have trust the message that the new policy will be beneficial.

Under the term 'social capital', therefore, we understood "the public good that is produced by the individuals for the subsequent removal of benefits" (Coleman, 1988). Many researchers have also argued that "social capital" — is often measured with questions regarding the level of trust.

In this work, we regarded Social Capital as an attribute of (an actor) a collectivity of government ( i.e. state apparatus) and Mass media institutions (collective entities of MSM and AIM media (Alternative Internet Media)) and Social Capital influence on another collectivity i.e. Russian society (the largest group in Russia) and society's level of trust.

Therefore, if an organization or institution possesses Social Capital, it has the capital to 
influence public minds i.e. it is trustworthy since one of the measurements of Social Capital is trust). Henceforth a trustworthy organization will be trusted (i.e. audience will have confidence in its message), in the absence of other influences. Consequently, in this work, we equated Social Capital with Trustworthiness and Trustworthiness with Confidence.

Nahapiet writes that relational Social Capital focuses on the quality of the relationship or interactions and the resources that are created or leveraged through the relationships. Its attributes include trust, trustworthiness, respect, and friendship. Cognitive social capital refers to "what people feel (values and perceptions)" (Harpham, 2008). It represents resources obtained from a common set of goals, a shared vision, and shared representations, interpretations, and systems of meaning among parties.

In this regard, trustworthiness is the ability to be relied upon; being regarded as honest or truthful. Thus, we can align trustworthiness with confidence. This ability can be regarded as capital, i.e., intangible assets owned by a person or organization or available or contributed for a particular purpose.

Of course, not all scientists share the opinion that trust is an element of social capital. In particular, E. L. Lesser (2000) believes that "trust is a separate concept and can be both a source of social capital and its result". That is, according to the scientist, trust and social capital support, strengthen and thereby ensure the existence of each other. Thus, even denying trust as a component of social capital, Lesser (Ibid.) cannot refute the close relationship between the two phenomena.

In this work, we relied on the model of Social Capital developed by the Organization for Economic Co-operation and Development, whereby the Social Capital (trustworthiness) of an organization or institution is made up of competence and values. In its turn competence is made up of responsiveness and reliability, while values consist of Integrity, Openness, Fairness, and Transparency, according to OECD (OECD Public Governance Reviews, 2017).

According to (OECD Public Governance Reviews, 2017) two different but complementary components that matter in understanding and analyzing systemic trust:

A. Competence or operational efficiency, capacity, and good judgment to deliver on a given mandate;

and

B. Values, or the underlying intentions and principles that guide actions and behaviors. 


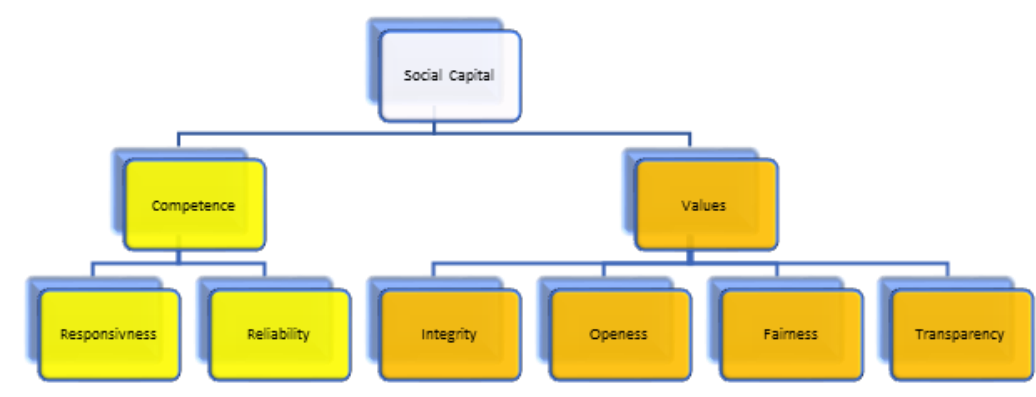

Figure 1. Independent variable: Social Capital elements

Therefore competence involves responsiveness that refers not only to how citizens receive public services but also to how an organization or an istitution listens to citizens and responds to their feedback; being about availability, access, timeliness, and quality, but also about respect, engagement, and response. Competence also involves the reliability-the capacity of the government institutions to respond effectively to a delegated responsibility to anticipate needs and thereby minimize uncertainty in the economic, social, and political environment facing people.

As Selznick wrote (p. 17), it is "infuse[d] with values beyond the technical requirements of the task at hand" (Selznick, 1957). This means that an organization has a distinctive sense of self and identity and its way and its beliefs become important for the society as well. Values involve integrity i.e., the way in which an organization or an istitution conducts itself and the degree to which they can be trusted to safeguard the public interests without the need for scrutiny, and therefore have the most direct influence on levels of trust in government as a whole. High standards of behavior reinforce the credibility and legitimacy of the an organization or an istitution and facilitate policy action by the government. It also involves openness - i.e., a dimension of trust, that reflects a renewed social contract between citizens and institution, where the state is co-operating with the public on public policies in their design and implementation. It also involves fairness i.e., a dimension of trust that addresses this concern by focusing on the consistent treatment of citizens by the government. Finally, it involves transparency i.e. integrity a value that can influence trust levels, embedding the policy-making process within transparency mechanisms allowing for greater accountability, e.g. Figure 1.

\subsection{Propensity to Trust}

An individual's disposition to trust correlates with the intention to trust when information about trustworthiness is ambiguous but does not correlate with the intention to trust when information about trustworthiness was clear. i.e., subjects with a high Propensity to Trust will trust any news source more, even when not sure about the trustworthiness of the received message; whereas the subjects with a low propensity, will trust the message only when sure of its veracity (Gill, K., \& \& McNally, 2005), therefore respondents with higher levels of Propensity to Trust will trust MSM news's message even though they might attribute low 
levels of social capital (expressed via its trustworthiness) to the Government and MSM institutions as such.

Based on the premise of trust antecedents being Trustworthiness and Propensity to Trust, in this work regarded Propensity to Trust as exerting a moderating influence on the relationship of trustworthiness (social capital) and trust (belief). Moderator within a "correlational analysis framework was a third variable that affects the zero-order correlation between the other two variables" (Reuben \& Kenny, 1986).

Rotenberg \& al. (2005) proposed the framework, with three fundamental bases of interpersonal trust is a personal trait varying from individual to individual, i.e.:

(a) Reliability, which refers to the fulfillment of word or promise (Rotenberg \& al., 2005).

(b) The emotional aspect refers to the reliance on others to refrain from causing emotional harm, such as being receptive to disclosures, maintaining the confidentiality of them, refraining from criticism, and avoiding acts that elicit embarrassment (Ibid.); and

(c) Honesty, which refers to telling the truth and engaging in behaviors that are guided by benign rather than malicious intent and by genuine rather than manipulative strategies (Ibid.).

\subsection{Personal Experience With Government Institutions}

Literature research suggested that citizens' experiences with government institutions can influence levels of trust in government. Individuals or groups that feel unfairly treated may decide not to co-operate even if the consequences are negative for them (Lind, 2002). On the other hand, when citizens feel fairly treated they could be willing to incur costs for the greater good provided they feel confident that others are doing the same. Researcher (Guerrero, 2011) asserts that the performance of public services is a predictor of trust in the government. At the same time (Christensen \& Lægreid, 2005) find that citizens who are more satisfied with specific public services generally have a higher level of trust in public institutions.

According to Laura Carstensen, in general, people tend to notice and remember the negative more than the positive (Reed, 2012). Citizens' perception of fairness is a critical dimension of trust both in the process and in the outcome. Citizens' experiences with public services can influence levels of trust in government, i.e., citizens must feel they have a real voice; that they are treated with respect; and to receive necessary feedback to their requests (OECDPublic Governance Reviews, 2017).

Some authors (e.g., (Guerrero, 2011) assert that the performance of public services is a predictor of trust in the government. Other researchers (Christensen \& Lægreid, 2005) indicate that citizens who are more satisfied with specific public services generally have a higher level of trust in public institutions. Additionally, when citizens feel fairly treated they are generally willing to incur costs for the greater good provided they feel confident that others are doing the same. Conversely, individuals that feel unfairly treated may decide not to co-operate even if the consequences are negative for them (Lind, 2002). 
Negative experience with the Russian government: was a control variable in our study that examined whether first-hand negative experience that subjects or their families had in dealing with the government bureaucracy (lies, unprofessionalism, unbefitting behavior by the government representatives) or similar rumored experience could have an effect on their trust in the MSM news, since people tend to notice and remember the negative more than the positive.

Negative experience with MSM: was a control variable in our study that examined whether first-hand negative experience that subjects or their families in relation with the MSM news (untruths, unprofessionalism, unbefitting behavior by the media representatives) or similar rumored experience could have an effect on their trust in the MSM news.

\section{Methods and Results}

The primary data collected in Moscow was principally presented in this work using the statistical method; the author used inferential statistics applied to the primary data to analyze correlation and regression levels. The research method was based on statistical models which allowed not only gathering opinions and assumptions but also finding out the numerical values of the studied indicators. The sample was constructed in proportion to the structure of the population of Moscow University youth i.e., 610500 students. The selective method used to form a sample aggregate allowed for the results of the quantitative study to be statistically reliable and extrapolated to larger groups of Russian youth.

The questionnaire provided statistically reliable numeric characteristics of the study. The data were weighted on the probability of selection and by socio-demographic parameters, while the maximum error size with a probability of $95 \%$ does not exceed $2.2 \%$. This study relied on a quantitative method to achieve the research goal, to solve the research problems, and to ensure high reliability of the results. Quantitative data analysis was performed using the survey responses from 401 undergraduate students in Moscow's ten universities.

Students aged 17-25 (both male and female) were asked to respond to the survey instrument anonymously and voluntarily, using their mobile gadgets to answer 101 questions in Google forms ${ }^{1}$ during orientation week. The sampling method for this study was non-probability. The sampling procedure was in two phases involving university students $70 \%$ of whom grew up outside of Moscow (according to official statistics), and thus represent Russia in general. Therefore, the simple random sampling technique was appropriate, and this gave each student within a particular university an equal chance of being asked to participate. Phase one included 30 students and phase 2 included 500 students, out of which 401 were selected.

\footnotetext{
${ }^{1}$ https://forms.gle/1SBJkwZrCxjtW5fE7 https://forms.gle/mJE57XX7PvpB7jHD7
} 


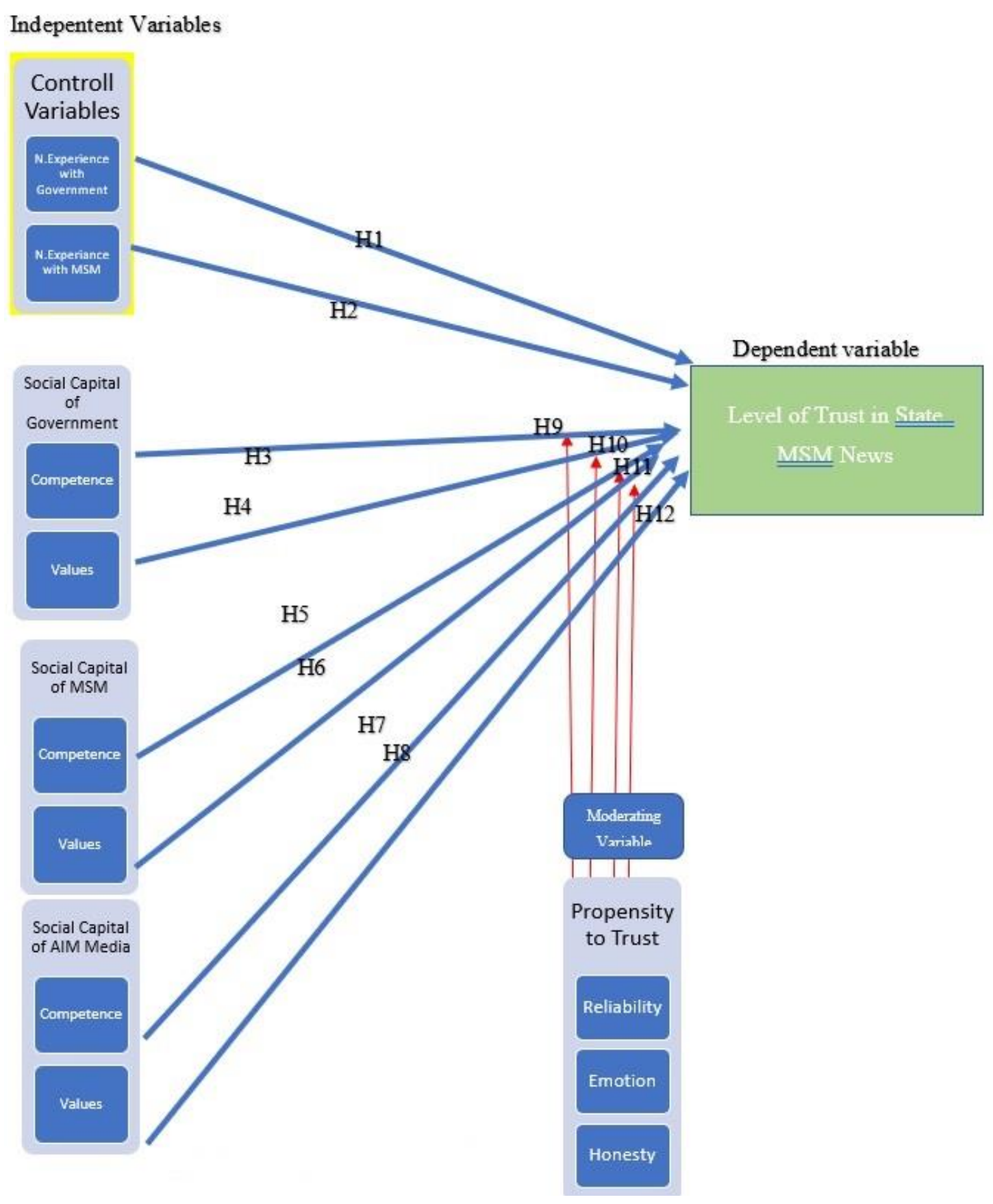

Figure 2. Conceptual Framework

\subsection{Measures}

The study used a survey instrument to collect empirical data from the field to answer objectives 1 and 2 of the study. The questionnaire was organized into five parts. The first section sought demographic information of respondents, the second section gathered Control Variables Negative Experience with Russian Government and State MSM, the third part solicited information on Trust in Russian State MSM, the fourth section dealt Social Capital of Russian Government, State MSM, and Alternative Internet Media. Finally, the fifth section evaluated Moderating Values i.e., the respondents' Propensity to Trust. 
Using the 7-point scale shown below, respondents were to indicate the extent to which they agreed or disagreed with the statements presented in a question form. A seven-point Likert scale with 1 being 'strongly disagrees to 7 strongly agree' for respondents to respond to the questions.

To ensure "reliability of the data" collected, the study adopted previously used scales that have been tested and found to have a high Alpha Cronbach between 0.8 and 0.9. The results of the reliability showed that most of the variables had an Alpha Cronbach that was statistically acceptable, e.g., Table 1.

Table 1. Reliability Test for Variables

\begin{tabular}{|l|l|l|l|}
\hline & Cronbach Alpha & Items \\
\hline Dependent Variable & 0.835 & 9 \\
\hline Gov. Competence & 0.915 & 7 \\
\hline Gov. Values & 0.891 & & 10 \\
\hline MSM Competence & 0.906 & 7 \\
\hline MSM Values & 0.848 & 10 \\
\hline AIM Competence & 0.949 & 7 \\
\hline AIM Values & 0.923 & 10 \\
\hline Control variable & 0.759 & 5 \\
\hline Moderating variable & 0.748 & 10 \\
\hline
\end{tabular}

\subsection{Results}

\subsubsection{Descriptive Statistics}

Table 2. Summary of descriptive statistics for the variables

\begin{tabular}{|l|l|l|l|l|l|}
\hline & $\mathrm{N}$ & Minimum & Maximum & Mean & Std. Deviation \\
\hline & Statistic & Statistic & Statistic & Statistic & Statistic \\
\hline DV-Trust in MSM & 401 & 12 & 83 & 23.37 & 11.498 \\
\hline $\begin{array}{l}\text { Government } \\
\text { Competence }\end{array}$ & 401 & 7 & 49 & 16.38 & авг.23 \\
\hline $\begin{array}{l}\text { Government } \\
\text { Values }\end{array}$ & 401 & 9 & 64 & 20 & 9.636 \\
\hline $\begin{array}{l}\text { MSM } \\
\text { Competence }\end{array}$ & 401 & 7 & 49 & 15.38 & 8.456 \\
\hline MSM Values & 401 & 12 & 62 & 22.99 & 8.183 \\
\hline AIM Competence & 401 & 7 & 49 & 23. дек & 11.512 \\
\hline AIM Values & 401 & 10 & 66 & 35.91 & 13.851 \\
\hline
\end{tabular}


All the participants were undergraduate students between the ages of 17 and 22, so this study did not collect their ages. Genders were represented almost equally, with male being 56, 86\% and female $43.14 \%$. More than half of the respondents relied on foreign MSM either rarely or sometimes. We argued that the ability to receive news in a foreign language reduces individual reliance on State Government TV and might put this individual to homeland MSM.

Our research has indicated that young students undoubtedly spend much time online, $16.71 \%$ spend 10 hours a day online, and both genders have more or less similar responses.

Overall, $71.8 \%$ of the respondents spent no time watching conventional TV. The cross-tabulation clearly indicated that those who are online are not watching conventional TV. For example, 9 people of 401 (2.24\%) respondents spent 1 hour watching TV and 5 hours online per day. Less time spent watching State propaganda frees people to receive alternative points of view. The number of hours spent on the Internet is inversely proportionate to the number of respondents. The number of hours watched TV is inversely proportionate to the number of hours spent on the internet. Our research indicated that even though young people are using the internet, they are not watching Mainstream Media TV online, instead, they are using it for social networks.

\subsubsection{Bivariant Analysis}

We have conducted correlation analysis (Table 4) for the independent and dependent variables, and came to the following conclusions:

There was sufficient evidence to conclude that:

there is a significant linear relationship between Levels of Negative personal, family, or rumored experience with MSM with the level of trust in MSM news because the correlation coefficient is significantly different from zero.

there is a significant linear relationship between the perceptions of the Russian government's level of competence with the level of trust in MSM news because the correlation coefficient is significantly different from zero.

that there is a significant linear relationship between the perceptions of the Russian government's level of values with the level of trust in MSM news because the correlation coefficient is significantly different from zero.

there is a significant linear relationship between the Perception of MSM level of competence with the level of trust in MSM news because the correlation coefficient is significantly different from zero.

there is a significant linear relationship between the Perception of MSM level of values with the level of trust in MSM news because the correlation coefficient is significantly different from zero.

there is a significant linear relationship between the Perception of Alternative Internet Media level of competence with the level of trust in MSM news because the correlation coefficient is significantly different from zero. 
there is an insignificant linear relationship between the Perception of Alternative Internet Media level of values with the level of trust in MSM news because the correlation coefficient is not significantly different from zero.

Table 3. Correlation and Regression Results

\begin{tabular}{|c|c|c|c|c|c|c|c|}
\hline & & & & & Regression & ANOVA & \\
\hline Variable & Hypothesis & Independent & Dependent & Correlation & R square & $\mathbf{F}$ & Sig \\
\hline Control & $\mathrm{H} 1$ & $\begin{array}{l}\text { Negative experience with } \\
\text { Government }\end{array}$ & TRUST in MSM & $-.408^{* *}$ & 0.166 & 79.698 & 0.000 \\
\hline Control & $\mathrm{H} 2$ & $\begin{array}{l}\text { Negative experience with } \\
\text { MSM }\end{array}$ & TRUST in MSM & $-.436^{* *}$ & 0.19 & 93.669 & 0.000 \\
\hline SC of Gov & $\mathrm{H} 3$ & Government Competence & TRUST in MSM & $.763^{* *}$ & 0.583 & 556.878 & 0.000 \\
\hline SC of Gov & $\mathrm{H} 4$ & Government Values & TRUST in MSM & $.772^{* *}$ & 0.595 & 586.849 & 0.000 \\
\hline $\begin{array}{ll}\text { SC } & \text { of } \\
\text { MSM } & \\
\end{array}$ & H5 & MSM Competence & TRUST in MSM & $.834^{* *}$ & 0.695 & 909.423 & 0.000 \\
\hline $\begin{array}{ll}\text { SC } & \text { of } \\
\text { MSM } & \\
\end{array}$ & H6 & MSM Values & TRUST in MSM & $.825 * *$ & 0.681 & 852.439 & 0.000 \\
\hline $\begin{array}{ll}\text { SC } & \text { of } \\
\text { AIM } & \\
\end{array}$ & $\mathrm{H} 7$ & AIM Competence & TRUST in MSM & $-.115^{*}$ & 0.13 & 5.354 & 0.021 \\
\hline $\begin{array}{l}\text { SC } \quad \text { of } \\
\text { AIM }\end{array}$ & $\mathrm{H} 8$ & AIM Values & TRUST in MSM & -0.041 & 0.002 & 0.67 & 0.414 \\
\hline
\end{tabular}

**. Pearson Correlation is significant at the 0.01 level (2-tailed).

\subsubsection{Regression Results}

This section deals with the results of the multiple regression techniques of the Independent Variables Government Competence and Values; MSM competence and Values, AIM competence and Values and the Dependent variable -The level of Trust in MSM news.

Independent variables indicate that negative (personal or rumored) experience dealing with the Russian government or State MSM did have a negative link with a level of trust in MSM. This variable in an experiment held constant (Table 4) to assess the relationship between multiple variables.

Variables 3-6 had a strong positive relationship with the Dependent Variable, in other words, Social Capital did influence the level of trust in MSM news.

The two components were used to measure the Independent Variable, i.e. Social Capital was measured by competence and values (which in their turn were made up of 6 components). From the literature review, it was necessary to use these two dimensions to measure the independent variable construct.

The dependent variable: Trust in MSM was measured with three components, objectivity, 
correctness, unnecessariness, reliability

Variable 7(AIM Competence) had a weak negative relationship with the dependent variable.

Variable 8 (AIM Values) had a negligible weak relationship with the dependent variable.

\subsubsection{Moderating Variables}

In this study, we utilized moderating variable Propensity to Trust that specified conditions under which a given predictor is related to an outcome i.e., the moderator explains 'when 'a Dependent Variable (Level of Trust MSM news) and Independent Variable (Social Capital) are related. Moderation implies an interaction effect, where introducing a moderating variable changes the direction or magnitude of the relationship between two variables.

In order to confirm a third variable (Propensity to Trust) is making a moderation effect on the relationship between the two variables: Dependent Variable and Independent Variables, we had to confirm that the nature of this relationship changes as the values of the moderating variable change.

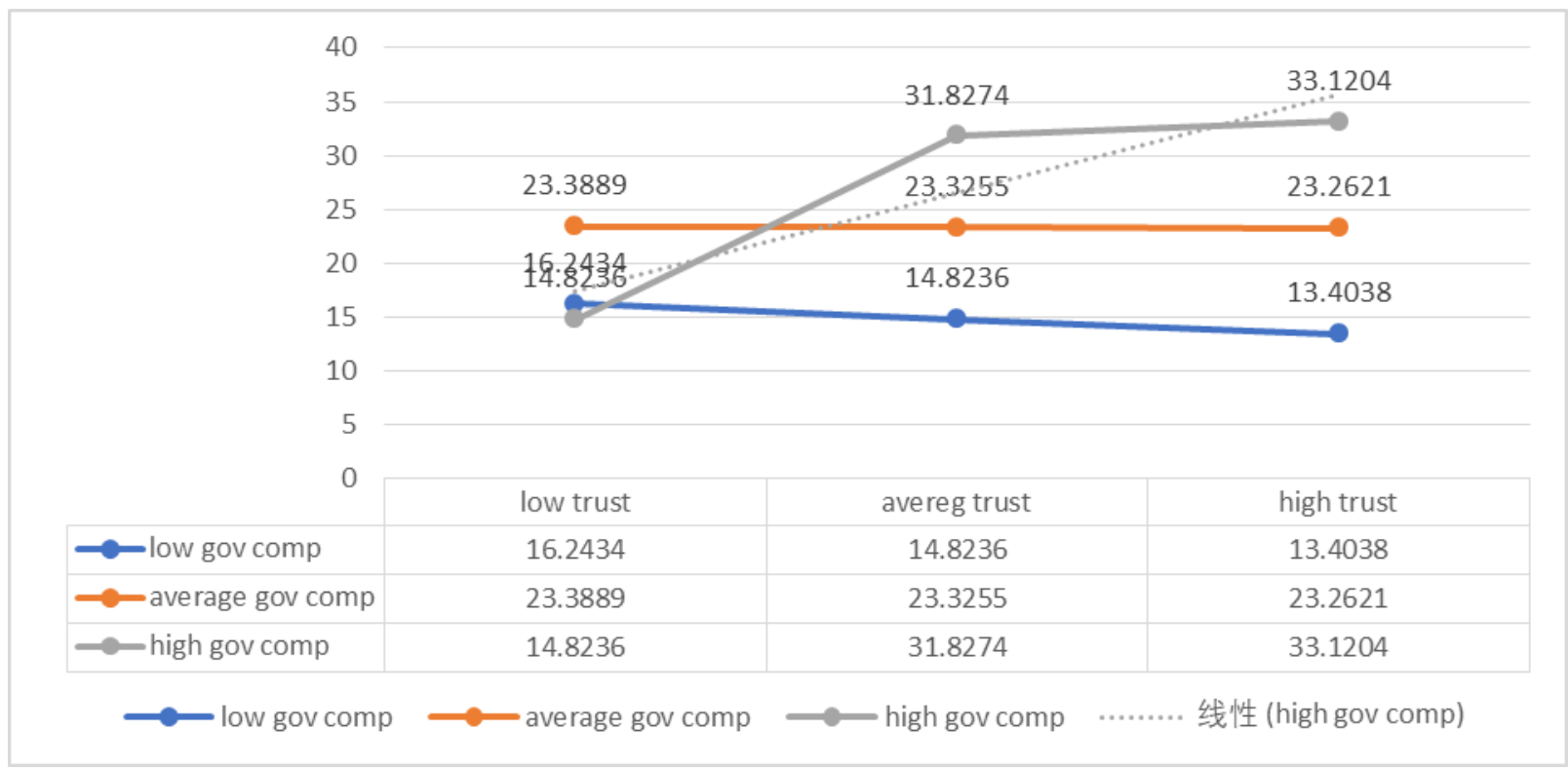

Figure 5. Hypothesis 9 interaction plot

Examination of the interaction plot for Hypothesis 9, showed an enhancing effect that as Propensity to Trust and Government Competency increased, MSM trust increased. Henceforth, students with a low Propensity to Trust and low regard for government competence had the lowest trust in MSM. Students with a high Propensity to Trust and high regard for government competence had the highest trust in MSM (Figure 5).

Examination of the interaction plot Hypothesis 10 showed an enhancing effect that as the Propensity to trust and Government Values increased, MSM trust increased. Henceforth, students with a low Propensity to Trust and low regard for government values had the lowest trust in MSM. Students with a high Propensity to Trust and high regard for government values had the highest trust in MSM. 
Examination of the interaction plot Hypothesis 11 showed an enhancing effect that as Propensity to Trust and MSM Competency increased, MSM trust increased. Henceforth, students with a low Propensity to Trust and low regard for MSM competence had the lowest trust in MSM. Students with a high Propensity to Trust and high regard for MSM competence had the highest trust in MSM.

Examination of the interaction plot Hypothesis 12 indicated Buffering effect (where increasing the moderator would decrease the effect of the predictor on the outcome) that as Propensity to Trust and MSM values increased, MSM trust increased, i.e., students with low Propensity to Trust and high regard for MSM values had the HIGHEST trust in MSM. Therefore, we can state that students with high regard for MSM values were moderately affected by their Propensity to Trust. Consequently, we can draw a conclusion that perception of values has an importance on the overall level of trust in the message received via MSM.

\subsubsection{Control Variable Negative Experience}

Our study utilized a control variable titled Negative experience, where respondents were asked to indicate whether they ever personally had negative experience dealing with the Russian government or State MSM or had heard rumors of others having had that experience. The control variables themselves were not of primary interest to our research, were they not held constant during the research they could strongly influence statistical results while testing the relative relationship of the dependent and independent variables (Table 3).

Table 4. Control variable Negative experience

\begin{tabular}{|l|l|l|l|l|l|l|}
\hline & N & Range & Minimum & Maximum & Mean & Std. Deviation \\
\cline { 2 - 7 } & Statistic & Statistic & Statistic & Statistic & Statistic & Statistic \\
\hline N ex MSM & 401 & 18 & 3 & 21 & 14. авг & 3.918 \\
\hline N ex GOV & 401 & 18 & 3 & 21 & 13.66 & 3.946 \\
\hline \hline
\end{tabular}

Our results suggest that our model is statistically significant. The following table illustrates the correlation matrix on the relationship between the individual component variables and the dependent variable as a whole. Correlation and other primary tests are presented since multiple regression assumes a linear relationship among the variables (Table 4).

Table 4. Summary of Hypotheses Tested

\begin{tabular}{|l|l|l|l|l|}
\hline Hypotheses & Independent Variables & Dependent Variables & \multicolumn{2}{l|}{ Results } \\
\cline { 3 - 5 } & & & Predicted & Empirical \\
\hline H1 & $\begin{array}{l}\text { Negative experience dealing with } \\
\text { the Russian Government }\end{array}$ & Level of Trust in MSM & $-\mathrm{ns}$ & $-\mathrm{ns} * *$ \\
\hline $\mathrm{H} 2$ & $\begin{array}{l}\text { Negative experience dealing with } \\
\text { the Russian MSM }\end{array}$ & Level of Trust in MSM & $-\mathrm{ns}$ & $-\mathrm{ns}^{* *}$ \\
\hline $\mathrm{H} 3$ & Government competence & Level of Trust in MSM & $-\mathrm{ns}$ & $+^{* *}$ \\
\hline
\end{tabular}




\begin{tabular}{|c|c|c|c|c|}
\hline \multirow[t]{2}{*}{ Hypotheses } & \multirow[t]{2}{*}{ Independent Variables } & \multirow[t]{2}{*}{ Dependent Variables } & \multicolumn{2}{|l|}{$\underline{\text { Results }}$} \\
\hline & & & Predicted & Empirical \\
\hline $\mathrm{H} 4$ & Government Values & Level of Trust in MSM & + & $+* *$ \\
\hline H5 & MSM Competence & Level of Trust in MSM & + & $+* *$ \\
\hline H6 & MSM Values & Level of Trust in MSM & + & $+* *$ \\
\hline $\mathrm{H} 7$ & AIM Competence & Level of Trust in MSM & $-n s$ & $-n s^{*}$ \\
\hline H8 & AIM Values & Level of Trust in MSM & $-n s$ & $-\mathrm{nNs}$ \\
\hline H9 & Moderation on $\mathrm{H} 3$ & Level of Trust in MSM & ++ & enhancing \\
\hline $\mathrm{H} 10$ & Moderation on $\mathrm{H} 4$ & Level of Trust in MSM & ++ & enhancing \\
\hline H11 & Moderation on $\mathrm{H} 5$ & Level of Trust in MSM & ++ & enhancing \\
\hline $\mathrm{H} 12$ & Moderation on $\mathrm{H} 6$ & Level of Trust in MSM & ++ & buffering \\
\hline
\end{tabular}

Where: '+'= positive and significant effect, ' + ns' = positive and not significant effect,

' - ns' = negative and significant effect ' $-\mathrm{nNs}$ ' = negative and not significant effect,

' ++ ' moderating enhancing effect $\quad * *=\mathrm{P}<0.001, *=\mathrm{P}<0.05$

\section{Discussion}

This study, based on the model of trust and distrust in the mass media, identified the key causes that influence the level of trust or distrust among the youth public in Moscow towards the media (traditional and new) within the framework of the socio-political system in modern-day Russia.

The two components were used to measure the independent variable, i.e., Social Capital was measured by competence and values (which in their turn were made up of 6 components). From the literature review, it was necessary to use these two dimensions to measure the independent variable construct.

In our research innate and highly personal variable Propensity to Trust was used as a moderator - a variable that specified conditions under which a given predictor (Social Capital) is related to an outcome (level of trust in MSM).

Our research clearly indicated that the Values of MSM had an influence on the Level of Trust in MSM message, irrespective of the level of individual Propensity of Trust, indicating that perhaps this component of Social Capital has more weight than the Competence component does.

When it comes to trust as a social phenomenon, and an element of Social Capital, manifested in the process of social interactions, we can also assume that, when deciding whether to trust or to distrust of a particular actor, entry or non-entry with him in partnership, the individual is often guided by the experience of previous contacts with the actor, one's own, if any, in the past, or other individuals' experiences. Thus, we were able to confirm that individuals with 
higher scores of reliability, emotion, and honesty transposed these values on the Mainstream Media messages, supposing that MSM and Government were also reliable, honest, and emphatic.

Moreover, an examination of the interaction plot of the moderating variable showed a Buffering effect (whereby increasing the moderator would decrease the effect of the predictor on the outcome) that as Propensity to Trust and MSM values increased, MSM trust increased, i.e., students with low Propensity to Trust and high regard for MSM values had the highest level of trust in MSM.

Therefore, we can state that students with high regard for MSM values were moderately affected by their Propensity to Trust. Therefore, we can draw a conclusion that perception of values has an importance on the overall level of trust in the message received via MSM. Thus, we were able to confirm that the Propensity of Trust is a moderating factor when it comes to Social Capital (Competence and Values) of both MSM and Government influencing the level of trust in MSM. Essentially, an important antecedent of trust actions involves characteristics of the trustor, namely one's Propensity to Trust.

Finally based on the empirical findings from the survey data we proposed a revised model of Trust in MSM; i.e., based on the empirical findings from the survey data of the effect on the level of trust on MSM, we hypothesized that perhaps Alternative Internet Media had altered hitherto considered an innate personal trait of the Propensity of Trust, which in its turn influenced the relationship between the Social Capitals of Government and MSM upon the level of Trust in State MSM.

\section{Conclusion and Implications for Future Research}

The results of our research indicate that there are several determinants of Trust in Russian state MSM news and the findings suggest that the current Russian Government's approach to increasing the level of competence of government and MSM is a half measure in itself, greatly offset by the presence of the alternative sources of information in the cyberspace (collectively referred to as AIM in this work). Our research identified various elements of Social Capital that influence the level of trust in MSM news as well as the Propensity to Trust, an innate quality highly specific to each respondent. Specifically, the values of Government and MSM directly influence the level of trust in the MSM news.

We were able to demonstrate a link between elements of the Social Capital of government and public institutions and levels trust in State MSM. At the same time, it became evident that lower levels of values of the Russian government and State MSM lowered the overall trust in state MSM news. Alternative Internet Media, on the other hand, having a higher level of values draws more and more audiences from the traditional MSM, which certainly indicated people's attitudes, not least of which is trust. At the same time, we demonstrated that people's innate Propensity to Trust also influences their level of trust in State MSM.

\section{Practical Implication}

Our findings suggest that the Russian government and the State MSM must work to improve 
their: Integrity i.e., the way in which representatives of an institution conduct themselves and the degree to which they can be trusted to safeguard the public interest without the need for scrutiny have the most direct influence on levels of trust in said public institutions. Undoubtedly high standards of behavior reinforce the credibility and legitimacy of government and facilitate policy action by the government.

Our findings imply that the Russian government and its State MSM must work to improve the Openness of public institutions to better understand people's needs if they are open and practice stakeholder engagement in the design and delivery of public policy and services. Openness, as a dimension of trust, reflects a renewed social contract between citizens and state, where the state is receptive to public policies and co-operating in their design and implementation.

Our findings suggest that the Russian government and its State MSM must work to improve the Fairness, that focuses on the consistent treatment of citizens and business by government, and protection of the pursuit of the benefit of society at large.

Finally, the Russian government and its State MSM must work to improve its Transparency that influences trust levels. The policy-making process embedded within transparency mechanisms allows for greater accountability.

It is worth remembering that values are not an abstract notion but are composed of various qualities themselves. Integrity is the way in which representatives of an institution conduct themselves on a daily basis and the degree to which they can be trusted to safeguard the public interest without the need for scrutiny and these two have the most direct influence on the levels of trust in public institutions such as MSM and governemmnht at large. Undoubtedly high standards of behavior reinforce the credibility and legitimacy of government and facilitate policy acceptaance by the population.

\section{Theoretical Implication}

The scientific novelty of this work is that it examined Social Capital as an attribute of (an actor) a collectivity of government (i.e., state apparatus) and Mass media institutions (collective entities of Mainstream Media and Alternative Internet Media) and Social Capital influence on another collectivity i.e., Russian society (the largest group in Russia). We argued that if an organization or institution has Social Capital, it has the capital to influence public minds i.e., it is trustworthy since one of the measurements of Social Capital is trust). Henceforth a trustworthy organization will be trusted, in the absence of other influences.

In our revised hypothesis, it was hypothesized that Propensity to Trust can also be altered over time, which brings us back to the old debate of Nature vs Nurture, which involves the extent to which particular aspects of behavior (Propensity to Trust) are a product of either inherited (i.e., genetic) or acquired (i.e., learned) influences.

The general conclusion of this work is that trust in State MSM is a multifaceted variable that is directly influenced by the Social Capital of the Russian Government and state MSM as it is perceived by the population segments. Nevertheless, since the Social Capital itself is 
composed of Competence and Values, there are numerous factors that could alter the balance, notwithstanding the fact that today the State MSM has a strong competitor i.e., Alternative Internet Media.

The limitation of this study was the fact that even though the problem of trust in the media has been thoroughly studied in the scientific literature (Kohring \& Matthes, 2007) ideas about media confidence need further systematization and require clarification.

Future research could also focus on the analysis of the trends and the charting of scenarios for the development of the new media as the global communication space, to aid in ensuring the national information security of the modern states whose population is becoming an object of the external information and communication impact, including manipulation via propaganda.

\section{Acknowledgement}

The research is part of my $\mathrm{PhD}$ dissertation towards an award of a doctor of philosophy degree, Development Administration from National Institute of Development Administration, NIDA.

\section{References}

Acquaah, M., \& Amoako-Gyampah, K. (2014). Measuring and Valuing Social Capital: A Systematic Review. Network for Business Sustainability South Africa. Retrieved from: nbs.net/knowledge

Adler, P. W. (2002). Social Capital: Prospects for a New Concept. The Academy of Management Review, 27(1), 17-40. https://doi.org/10.5465/amr.2002.5922314

Bourdieu, P. (1985). The Social Space and the Genesis of Groups. Theory and Society, 14, 723-744. https://doi.org/10.1007/BF00174048

Christensen, T., \& Lægreid, P. (2005). Trust in government: The relative importance of service satisfaction, political factors, and demography. Public Performance \& Management Review, 28(4), 487-511.

Coleman, J. (1988). Social Capital in the Creation of Human Capital. American Journal of Sociology, 94, 95-120. https://doi.org/10.1086/228943

Colquitt, J. A., Scott, B. A., \& LePine, J. A. (2007). Trust, trustworthiness, and trust propensity: A meta-analytic test of their unique relationships with risk taking and job

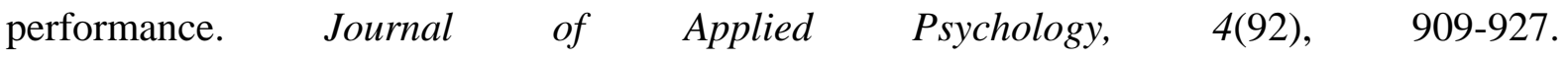
https://doi.org/10.1037/0021-9010.92.4.909

Colquitt, J. A., Scott, B. A., \& LePine, J. A. (2007). Trust, trustworthiness, and trust propensity: A meta-analytic test of their unique relationships with risk taking and job performance. 4(92), 909-927. https://doi.org/10.1037/0021-9010.92.4.909

Corritore, C. L. (2003). On-line trust: concepts, evolving themes, a model. International Journal of Human-Computer Studies, $\quad 58(6), \quad 737-758$. https://doi.org/10.1016/S1071-5819(03)00041-7 
Cote, S. H. (2001). The Well-being of Nations. The role of human and social capital.

Cunningham, J. B. (1978). A Systems-Resource Approach for Evaluating Organizational Effectiveness. Human Relations, 31(7), 631-656. https://doi.org/10.1177/001872677803100705

DeFilippis, J. (2001, 01 01). The myth of social capital in community development. Housing Policy Debate., 4, 781-806.

Dolfsma, W., \& Dannreuther, C. (2003). Subjects and boundaries: Contesting social capital-based policies. Journal of Economic Issues, 37, 405-413. https://doi.org/10.1080/00213624.2003.11506588

Edelman. (2019). 2019 EDELMAN TRUST BAROMETERGlobal Report. Edelman. Retrieved from

https://www.edelman.com/sites/g/files/aatuss191/files/2019-02/2019_Edelman_Trust_Barom eter_Global_Report.pdf

Forsyth, P. B. (2011). Collective trust. Why schools can't improve.

Fukuyama, F. (1996). Trust: Social Virtues and the Creation of Prosperity. Simon and Schuster.

Gill, H. B., K., F. J., \& \& McNally, J. (2005). Antecedents of trust: Establishing a boundary condition for the relation between propensity to trust and intention to trust. Journal of business and psychology, 19(3), 287-302. https://doi.org/10.1007/s10869-004-2229-8

Guerrero, A. (2011). Rebuilding trust in government via service delivery: The case of Medellin, Colombia. Washington, DC: World Bank.

Harpham, T. (2008). The Measurement of Community Social Capital Through Surveys. https://doi.org/10.1007/978-0-387-71311-3_3

Holmes, J. (1985). Trust in Close Relationships. Journal of Personality and Social Psychology. https://doi.org/10.1037//0022-3514.49.1.95

J. David Lewis, A. W. (1985, June). Trust as a Social Reality. Social Forces, 63(4), 967-985. https://doi.org/10.1093/sf/63.4.967

Jones, S. L. (2016). Diagnosing the locus of trust: A temporal perspective for trustor, trustee, and dyadic influences on perceived trustworthiness. Journal of Applied Psychology, 101(3), 392. https://doi.org/10.1037/ap10000041

Key, V. O. (1966). The Responsible Electorate. New York: Vintage Books. https://doi.org/10.4159/harvard.9780674497764

Kiyonari, T. Y. (2006). Does Trust Beget Trustworthiness? Trust and Trustworthiness in Two Games and Two Cultures: A Research Note. Social Psychology Quarterly, 3, 270-283. https://doi.org/10.1177/019027250606900304 
Kohring, M., \& Matthes, J. (2007). Trust in news media: Development and validation of a multidimensional scale. Communication research, 34(2), 231-252. https://doi.org/10.1177/0093650206298071

Lesser, E. (2000). Leveraging Social Capital in Organizations. https://doi.org/10.1016/B978-0-7506-7222-1.50004-0

Lewicki, R. (1998). Trust and Distrust: New Relationships and Realities. The Academy of Management Review., 23. https://doi.org/10.2307/259288

Lind, E. A. (2002). When fairness works: Toward a general theory of uncertainty management. Research in organizational behavior, 24, 181-223. https://doi.org/10.1016/S0191-3085(02)24006-X

Lippmann, W. (1922). Public Oppinion. Harcourt, Brace.

Lipset, S. M. (1968). Revolution and Counterrevolution: Change and Persistence in Social Structures. Retrieved from https://www.questia.com/read/14879224/revolution-and-counterrevolution-change-and-persis tence

Lucassen, T. (1983). Trust in Online Information. AEEnschede, The Netherlands: Universiteit Twente CTIT.

Luhmann, N. (2000). The Reality of the Mass Media. Stanford University Press.

Luhmann, N. (2000). The reality of the mass media. Stanford,CA: Stanford University Press.

Mayer, R. D. (1995). An Integrative Model of Organizational Trust. The Academy of Management Review, 3, 709-734. https://doi.org/10.5465/amr.1995.9508080335

Narayan, D. (2001). A Dimensional Approach to Measuring Social Capital: Development and Validation of a Social Capital Inventory. Current Sociology, 49, 59-102. https://doi.org/10.1177/0011392101049002006

OECDPublic Governance Reviews. (2017). Trust and Public Policy: How Better Governance Can Help Rebuild Public Trust. Paris: OECD Publishing,. https://doi.org/10.1787/9789264268920-en

Putnam, R. D. (1995). Bowling Alone: America's Declining Social Capital. Journal of Democracy, 6(1), 65-78. https://doi.org/10.1353/jod.1995.0002

Reed, A. E. (2012). The theory behind the age-related positivity effect. Frontiers in psychology, 3(39). https://doi.org/10.3389/fpsyg.2012.00339

Reuben, B. M., \& Kenny, D. A. (1986). The moderator-mediator variable distinction in social psychological research: Conceptual, strategic, and statistical considerations. ournal of personality and social psychology, 51(6), 1173. https://doi.org/10.1037/0022-3514.51.6.1173 


\section{Macrothink}

Journal of Public Administration and Governance ISSN 2161-7104 2021, Vol. 11, No. 2

Rotenberg, K. (2019). The Relation between Interpersonal Trust and Adjustment: Is Trust Always Good? Trust in Contemporary Society, 161-174. https://doi.org/10.1163/9789004390430_010

Rotenberg, K. J., \& al., e. (2005). Construction and validation of a children's interpersonal trust belief scale. British Journal of Developmental Psychology, 23(2), 271-293. https://doi.org/10.1348/026151005X26192

Rousseau, D. M. (1998). Not so different after all: A cross-discipline view of trust. Academy of Management Review, 23(3), 39. https://doi.org/10.5465/amr.1998.926617

Seligman, A. B. (1998). Trust and sociability: On the limits of confidence and role expectations. American Journal of economics and sociology, 57(4), 391-404. https://doi.org/10.1111/j.1536-7150.1998.tb03372.x

Selznick, P. (1957). Leadership in administration: A sociological interpretation. . Evanston, IL: Row Peterson.

Sweller, J. (1988, 04 2). Cognitive Load During Problem Solving: Effects on Learning. Cognitive Science, 12(2). https://doi.org/10.1207/s15516709cog1202_4

Udy Jr, S. H. (1959). Bureaucracy and Rationality in Weber's Organization Theory. An Empirical Study. American Sociological Review, 91-795. https://doi.org/10.2307/2088566

Vlaar, P. W. (2007). On the Evolution of Trust, Distrust, and Formal Coordination and Control in Interorganizational Relationships: Toward an Integrative Framework. Group \& Organization Management,, 32(4). https://doi.org/10.1177/1059601106294215

Weber, M. (2015). Weber's Rationalism and Modern Society,. (T. Waters, \& D. Waters, Eds.) New York: Palgrave MacMillan.

York, R. (2018). Control variables and causal inference: a question of balance, International Journal of Social Research Methodology,. 21(6), 675-684. https://doi.org/10.1080/13645579.2018.1468730

ZIRCON. (2019). Obraz_zhurnalistov-2018. Retrieved from http://www.zircon.ru/upload/iblock/b0d/Obraz_zhurnalistov-2018_otchet.pdf

\section{Copyright Disclaimer}

Copyright for this article is retained by the author(s), with first publication rights granted to the journal.

This is an open-access article distributed under the terms and conditions of the Creative Commons Attribution license (http://creativecommons.org/licenses/by/4.0/). 